Orijinal araştırma-Original research

http://dx.doi.org/10.7197/1305-0028.1689

\title{
Hipertansif hastalarm ailelerinde Apo E gen polimorfizmleri ve kan lipit profillerinin değerlendirilmesi
}

\section{Assessment of Apo E gene polymorphism and blood lipid profile in families of patients with hypertension}

\section{Abdullah Sezai Doğan, Cem Yenicesu*, Mustafa Haki Sucaklı, Öztürk Özdemir, Yeltekin Demirel}

Aile Hekimliği (Dr. A. S. Doğan), Manavgat Aile Sağlığı Merkezi, TR 07600 Antalya, Aile Hekimliği Anabilim Dalı (Yrd. Doç. C. Yenicesu, Prof. Dr. Y. Demirel), Cumhuriyet Üniversitesi Tıp Fakültesi, TR-58140 Sivas, Aile Hekimliği Anabilim Dalı (Doç. Dr. M. H. Sucaklı), Sütçü İmam Üniversitesi Tıp Fakültesi, TR-46100 Kahramanmaraș, Tıbbi Genetik Anabilim Dalı (Prof. Dr. Ö. Özdemir), Onsekiz Mart Üniversitesi Tıp Fakültesi, TR-17020 Çanakkale

\section{Özet}

Amaç. Bu çalışmamızda, hipertansif hastaların ailelerinde Apo E gen polimorfizmleri ve kan lipit profillerinin değerlendirilmesi amaçlanmıştır. Yöntem. Çalışmamız iki aşamada planlandı. İlk aşamada; 45 yaş altı popülasyonda CVD (CardiovascularDisease) gen mutasyonunu değerlendirmek için, esansiyel hipertansiyona sahip 50 kişilik olgu grubu ve aynı yaş grubu ve cinsiyette tansiyonu normal sınırlarda olan 50 kişilik kontrol grubu seçildi. Çalışmanın ikinci aşamasında, olgu grubundaki ACE gen polimorfizmi DD homozigot olan hastaların birinci derece akrabalarında (50), genetik polimorfizm açısından değerlendirildi. Bulgular. Olgu grubunda ApoE3/E4 alleline sahip olanların \%88,9'unda ailede hipertansiyon hikayesi mevcuidi. Aynı şekilde E3/E2 genotipine sahip olanların hepsinde aile hikayesi pozitif idi. Olgu grubunda, 5 kişide (\%10) ApoE E3/E2 gen polimorfizmi, 9 kişide (\%18) ApoE E3/E4 gen polimorfizmi mevcuttu. Kontrol grubunda bu sayılar sirasiyla 7 ve 3 (\%14 ve \%6) idi. Olgu grubunda ApoE3/E2 gen polimorfizmi, kontrol grubundan daha yüksekti ( $>00,05)$. Olgu grubunda E3/E4 genotipi, kontrol grubundan yüksekti; ancak bu istatiksel olarak anlamlı bulunmadı. Total kolesterolü $200 \mathrm{mg} / \mathrm{dL}$ ve üzeri olanların \%62,5'i olgu grubundaydı ve bu oran, kontrol grubuna göre $(\% 37,5)$ istatistiksel olarak anlaml şekilde yüksekti $(\mathrm{p}<0,05)$. Aile grubunda bu oran \%66 idi. HDL ortalama değerleri 3 grupta da düşüktü (olgu grubunda 41,93 $\pm 11,22 \mathrm{mg} / \mathrm{dL}$, aile grubunda 40,4 $\pm 13,4$ ve kontrol grubunda $44,93 \pm 15,24 \mathrm{mg} / \mathrm{dL}$ ). Olgu grubunda LDL ortalamas1 $133,6 \pm 32,2 \mathrm{mg} / \mathrm{dL}$, aile grubunda $137,8 \pm 30,8 \mathrm{mg} / \mathrm{dL}$ ve kontrol grubunda $123,4 \pm 32,9 \mathrm{mg} / \mathrm{dL}$ olarak belirlendi. Total kolesterol/HDL kolesterol oran1; olgu grubunda 4,9 $\pm 1,4$, aile grubunda 5,7 $\pm 2,3$ ve kontrol grubunda $4,7 \pm 1,8$ idi. Aile grubunda hipertansiyon prevalans1 $\% 56$ idi (45 yaş ve altı bireylerde \%37). 40 yaş öncesi hipertansiyon tanısı alanların oranı \%42,9 idi. Sonuç. Hem olgu hem de aile grubunda kolesterol, LDL değerleri ve total kolesterol/HDL oranının yüksek, HDL değerlerinin düşük olması için gerekli hayat tarzı değişikliklerinin yapılması gerektiğini düşündürmektedir. Sonuç olarak, hipertansiyon etiyolojisi sorgulanırken, genetik faktörler de göz önünde tutulmalıdır ve hipertansiyondan sorumlu tutulan genlerle ilgili çalışmalar yapılmalıdır. Ayrıca hipertansif hastalar değerlendirilirken tüm aile bireylerinin taranması yapılarak, hipertansiyon ve diğer kardiyovasküler hastalıklar açısından takip edilmelidir. Özellikle 40 yaş öncesi hipertansiyon tanısı konmuş olan hastalar ve ailesi hem genetik açıdan, hem de diğer risk faktörleri (VKİ, lipid profili, sigara, alkol) açısından takip edilmeli ve hayat tarzı değişikliklerinin uygulanması sağlanmalıdır.

Anahtar sözcükler: Hipertansiyon, lipid profili, genetik yatkınlık

\begin{abstract}
Aim. It is observed in studies that hypertension is a feature of familial and a variety of gene polymorphism is associated with hypertension. Method. This study was planned in two stages. At the first stage; to evaluate gene mutation, in population under the age of 45 CVD (CardiovascularDisease) case group of 50 persons with essential hypertension and at the same age group and sex, within normal blood pressure limits in a control group of 50 people was selected.In
\end{abstract}


the second stage, cases of first-degree relatives of patients with homozygous polimorfizm DD ACE gene group (parents and siblings) family group of 50 people, were evaluated for genetic polymorphism. Results. Those with cases of allele ApoE3/E4 group, 88.9\% had a family history of hypertension. In the same way, in all of those with the E3/E2 genotype, family history was positive. In the case group, 5 people (10\%) E3/E2 ApoE gene polymorphism, 9 patients (18\%) had APOE E3/E4 gene polymorphism. In the control group, these numbers was about respectively, 7 , and $3(14 \%$ and 6\%).In the control group, ApoE3/E2 gene polymorphism, higher than control group ( $\mathrm{p}>0.05)$. Case group E3/E4 genotype, higher than the control group; but this difference was not statistically significant. Total cholesterol $200 \mathrm{mg} / \mathrm{dL}$ and above those $62.5 \%$ of people were in the case group and this ratio compared to control group $(37.5 \%)$ were significantly higher $(\mathrm{p}<0.05)$. In the family group, this rate was $66 \%$. The mean values of HDL was lower in the 3 groups (case group, $41.9 \pm 11.2$, family group, $40.4 \pm 13.4$ and control group $44.9 \pm 15.24$ $\mathrm{mg} / \mathrm{dL})$. Mean LDL values were determined as $133.6 \pm 32.2 \mathrm{mg} / \mathrm{dL}$ in case group, $137.8 \pm 30.8$ $\mathrm{mg} / \mathrm{dL}$ in family group, and $123.4 \pm 32.9 \mathrm{mg} / \mathrm{dL}$ in control group. Total cholesterol/HDL cholesterol ratios were $4978 \pm 1.41$ in case group, $5.7 \pm 2.3$ in family group and $4670 \pm 1.83$ in control group. The prevalence of hypertension was $56 \%$ in family group, (37\% in individuals 45 years and under). $42.9 \%$ of those diagnosed before the age of 40 had hypertension. Conclusion. Both the case and the family group, cholesterol, LDL levels and total cholesterol/HDL ratio is high, low HDL levels, lipid values should be within normal limits suggests that lifestyle changes are necessary to bring. As a result, while the etiology of hypertension is querying, also genetic factors should be considered in, and studies on genes and hypertension should be held responsible.In addition, hypertensive patients should be monitorized for hypertension and other cardiovascular diseases by screening of all family members while they are being evaluated. Especially patients with hypertension was diagnosed before the age of 40 and their families should be monitored for both genetic and other risk factors (BMI, lipid profile, smoking, alcohol). Lifestyle changes which are important for hypertension prevention and control of hypertension should be employed.

Keywords: Hypertension, lipid profile, genetic predisposition

Geliş tarihi/Received: 14 Temmuz 2012; Kabul tarihi/Accepted: 25 Kasım 2014

\author{
*İletişim adresi: \\ Dr. Cem Yenicesu, Aile Hekimliği Anabilim Dalı, Cumhuriyet Üniversitesi Tıp Fakültesi, TR- \\ 58140 Sivas. E-posta: uz.drcem@ hotmail.com
}

Bu çalışma, Cumhuriyet Üniversitesi Tıp Fakültesi Etik Kurul Başkanlığı tarafından 04.09.2007 tarihinde onaylanmıștır.

\title{
Giriş
}

Hipertansiyon dünyada morbidite ve mortalitenin önde gelen nedenlerinden biridir ve dünya genelinde 1 milyar kişinin hipertansiyon hastası olduğu bilinmektedir [1-3]. Sadece ABD'nde 50 milyondan fazla kişi antihipertansif ilaç tedavisi almaktadır [1-3]. Hipertansiyon tedavisinin, inme ve iskemik kalp hastalığı insidans ve prevalansında çok belirgin düşüşler sağladığg gösterilmiştir [3, 4].

Türkiye'de 2003'te yürütülen nüfus tabanlı kesitsel epidemiyolojik bir çalışmada, hipertansiyon prevalansı (yaşa ve cinse ayarlı) \%31,8 olarak belirlenmiştir [5]. TEKHARF Çalışmasında, sistolik kan basıncı (SKB) $140 \mathrm{mmHg}$ ve/veya diyastolik kan basıncı (DKB) $90 \mathrm{mmHg}$ üzerinde olanların oranının erişkin nüfusun üçte birini oluşturduğu saptanmiştır [6].

Araştırmalar sonucunda, genetik faktörlerin hipertansiyon oluşumundaki rolünün \%30-60 oranında olduğu gösterilmiştir $[2,7]$. Aile hikayesi pozitifliği ve hipertansiyon görülme sıklı̆gı ile ilgili yapılan çalışmalarda; ailesinde hipertansiyon olanlarda hipertansiyon görülme riskinin arttı̆̆ ve hipertansiyonlu aile üyesi sayısı arttıkça, riskin de arttığı gösterilmiştir [8-12]. 
Esansiyel hipertansiyonla anjiotensin dönüştürücü enzim (ACE) gen polimorfizminin birlikteliğini araştıran bir çalışmada, ACE DD genotipinin ciddi hipertansiyon hastalarında ve pozitif aile hikayesi olanlarda predispozan etkiye sahip olduğu saptanmıştır [13].

Kardiyovasküler hastalıklar için hipertansiyonla birlikte diğer önemli bir risk faktörü hiperlipidemidir. Hiperlipidemi, özellikle de LDL yüksekliği; koroner arter hastalı̆̆1 $(\mathrm{KAH})$ için major risk faktörlerinden biridir. Hiperlipidemiye sigara kullanımı ve/veya yüksek kan basıncı eşlik ederse bu risk artmaktadır. Gelecek on yıllık periyodda gelișecek koroner kalp hastalığı mutlak riskinin belirlenmesi için kullanılan Framingham Skor Sistemine göre; yaş, cinsiyet, sigara, total kolesterol, HDL, sistolik kan basıncı risk faktörleri olarak değerlendirilmektedir [14]. Bu nedenle hipertansiyon kontrolü yanında, lipid düzeylerinin de kontrol edilmesi önem taşımaktadır. Dislipideminin takip eden hipertansiyon gelişimine öncülük edebildiği öne sürülmektedir $[15,16]$.

Araştırmalar göstermiştir ki, apolipoproteinlerdeki genetik değişimlerin, KAH'nın gelişiminde bireylerarası farklılıkları belirleyen en önemli faktörlerden biridir [17].

Apolipoprotein E (Apo E)'nin LDL reseptörleri için ligand olarak görev yapan ve bu reseptörlerle etkileşimi sonucu çeşitli vücut hücrelerindeki lipidlerin özellikle kolesterolün taşınmasına katılan bir plazma proteini olduğu gösterilmiş ve Apo E2 allelinin ise serum trigliserid düzeylerinde artş̧a neden olduğu öne sürülmüsstür [18]. Apolipoprotein E geni 19. kromozom üzerinde yer almaktadır. Apo E'nin üç esas izoformunun, tek bir gen lokusunda üç allelin $(\varepsilon 2, \varepsilon 3, \varepsilon 4)$ ürettiği Apo E2, E3 ve E4 olduğu kabul edilmiştir [18].

LDL reseptörü için ligand görevi gören Apo E’nin çeşitli popülasyonlardaki çalışmalarda kardiyovasküler hastalığa öncülük eden ateresklerozu etkilediği vurgulanmaktadır. Apo E ve lipid profiliyle esansiyelhipertansiyonun ilişkisini araştıran bir çalışmada; Apo E epsilon 4 allelinin hasta grupta kontrol grubuna göre yaklaşık iki kat yüksek insidansta olduğu gözlemlenmiştir. Aynı şekilde; Apo E epsilon 4 allelinin aile hikayesi pozitif grupta, aile hikayesi negatif gruba göre yaklaşık iki kat yüksek olduğu gösterilmiştir. Apo E epsilon 4 alleli olan hastalar olmayanlara göre, daha yüksek LDL ve total kolesterol seviyelerine sahip olduğu gözlemlenmiştir [19]. Diğer bir çalışmada; hipertansif hastalarda apolipoprotein E fenotip E3/2 ve epsilon2 allelinin prevalansının daha yüksek olduğu gözlemlenmiştir [20]. Çeşitli toplumlarda yapılan çalışmalarda, Apo E4'ün KAH, yüksek plasma total kolesterol ve LDL ile ilişkili olduğu gösterilmiştir [21]. Koroner arter hastası erkeklerde yapılan Apo E fenotipleme çalışmalarında, plazma total kolesterol ve $\mathrm{LDL}$ düzeyinin en çok $\mathrm{E} 4 / 4$, en az $\mathrm{E} 3 / 2$ tarafindan arttığ 1 gösterilmiştir $(\mathrm{E} 3 / 2<\mathrm{E} 3 / 3<\mathrm{E} 3 / 4<\mathrm{E} 4 / 4)[22,23]$. Bu çalışmalar Apo E4'ün ateroz için bir risk faktörü olduğunu, ayrıca Apo E4 allelinin koroner arter hastalığının şiddetini belirlediğini göstermektedir [24-26]. Ancak, bu ilişkinin kesin olarak ortaya konması için daha çok çalışmaya ihtiyaç vardır.

Apo E ve lipid parametreleri arasındaki ilişkiyi araştıran çalışmalarda, plazma lipid seviyelerini belirlemekte Apo E'deki değişikliklerin rol oynadığı belirlenmiştir [27].

Türkiye'de yapılan bir çalışmada, E3/4 allelinin kontrol grubuna göre iki kat fazla olduğu belirlenmiştir. Ayrıca E4 allelinin orta derece hipertansiyonu olanlarda daha yüksek oranda son organ hasarına (sol ventrikülhipertrofisi, dilate sol atrium, retinopati) neden olduğu gözlemlenmiştir [28].

Bizim toplumumuzda, genetik polimorfizm ile ilgili sınırlı sayıda araştırma bulunduğu gözönüne alındığında, hipertansif ailelerde hipertansiyonun genetik yatkınlığını ortaya koymanın hem hipertansiyon tedavisinin belirlenmesine, hem de hipertansiyon ve kardiyovasküler hastalık riskinin azaltılmasına katkısı olacağını düşünmekteyiz. Ayrıca; genetik yatkınlığı bulunan ailelerin takip altına alınarak, hipertansiyon ve kardiyovasküler hastalık riskini ve/veya genç yaşlarda bu hastalıklara yakalanmasını önlemek için gerekli olan hayat tarzı değişiklikleri ile ilgili eğitimlerim verilmesini sağlamayı amaçlamaktayız. 


\section{Gereç ve yöntem}

Çalışmamız iki aşamada planlandı. İlk aşamada; 45 yaş altı popülasyonda CVD (cardiovascular disease=kardiyovasküler hastalık) gen mutasyonunu değerlendirmek için, Esansiyel hipertansiyona sahip 50 kişilik olgu grubu ve aynı yaş grubu ve cinsiyette tansiyonu normal sınırlarda olan 50 kişilik kontrol grubu oluşturuldu. Olgu grubu, Cumhuriyet Üniversitesi Tıp Fakültesi Kardiyoloji Polikliniği'ne başvuran hastalardan seçilirken, kontrol grubunun seçimi soruşturma tekniğiyle hastane ortamından yapıldı.

Olgu grubu, esansiyel hipertansiyon tanısı dışında herhangi bir hastalı̆̆ı olmayan bireylerden oluşturuldu. Kontrol grubu; kişilerin sorgulanması ya da hasta dosyalarının incelenmesi sonucu klinik ve laboratuar olarak herhangi bir kardiyovasküler, serebrovasküler ve vasküler hastalık tanısı olmayan bireylerden oluşturuldu.

Çalışmanın ikinci aşamasında, olgu grubundaki ACE gen polimorfizmi D/D homozigot olan hastaların ailesinde genetik yatkınlık olup olmadığını belirlemek için, bu hastaların birinci derece akrabası (anne-baba ve kardeşler) 50 kişiden oluşan aile grubu, genetik polimorfizm açısından değerlendirildi. Veriler SPSS (ver. 13,0) programıyla bilgisayara girildi. Veri analizi, tanımlayıcı istatistikler, $X^{2}$ ve t-testi kullanılarak yapıldı. " $p<0,05$ " anlamlılık sınırı olarak kabul edildi.

\section{Bulgular}

Olgu ve kontrol grubunun \%64'ü kadın ( $n=32), \% 36$ 's1 erkekti $(n=18)$. Olgu grubundaki hastaların ortalama yaşı 38,3 $\pm 6,9$ iken, kontrol grubundaki katılımcılarda bu değer 37,1 $\pm 6,7$ idi. VKİ ortalaması; olgu grubunda, kontrol grubundan daha yüksekti (sırasıyla; $28,5 \pm 4,5$ ve $25,9 \pm 4,5 \mathrm{~kg} / \mathrm{m}^{2}$ ) (Tablo 1 ).

Olgu grubunda kolesterol $(198,9 \pm 38,5 \mathrm{mg} / \mathrm{dL}), \mathrm{LDL}(133,6 \pm 32,2 \mathrm{mg} / \mathrm{dL})$ ve trigliserid $(135,7 \pm 82,9 \mathrm{mg} / \mathrm{dL})$ ortalama değerleri, kontrol grubundaki ortalama değerlerden (sirasiyla; $188,5 \pm 41,2,123,4 \pm 32,9$ ve 104,6 \pm 68,8 mg/dL) daha yüksek iken; HDL ortalama değerleri açısından kontrol grubu ortalaması daha yüksekti (olgu grubu: 41,9 \pm $11,2 \mathrm{mg} / \mathrm{dL}$; kontrol grubu: 44,9 $\pm 15,2 \mathrm{mg} / \mathrm{dL}$ ). Total kolesterol/HDL ortalamas1 (TK/HDL), olgu grubunda 4,9 $\pm 1,4 \mathrm{mg} / \mathrm{dL}$, kontrol grubunda 4,7 $\pm 1,8 \mathrm{mg} / \mathrm{dL}$ 'ydi. Olgukontrol grubu sosyodemografik özellikleri, tansiyon, lipid ve akş değerleri Tablo 1'de görülmektedir.

Tablo 1. Olgu-kontrol grubu sosyodemografik özellikleri, tansiyon, lipid ve akış feğerleri.

\begin{tabular}{|c|c|c|c|c|c|c|c|}
\hline \multirow[t]{2}{*}{ Özellik } & \multicolumn{2}{|c|}{ En düşük değer } & \multicolumn{2}{|c|}{ En yüksek değer } & \multicolumn{2}{|c|}{ Ortalama \pm S. S. $* * *$} & \multirow[t]{2}{*}{$\mathbf{p}$} \\
\hline & $\mathbf{V} *$ & $\mathbf{K} * *$ & $\mathbf{V}$ & $\mathbf{K}$ & $\mathbf{V}$ & $\mathbf{K}$ & \\
\hline Yaş & 16 & 16 & 45 & 45 & $38,3 \pm 6,9$ & $37,1 \pm 6,7$ & 0,414 \\
\hline Boy & 150 & 147 & 185 & 183 & $166,8 \pm 7,8$ & $164,1 \pm 8,5$ & 0,104 \\
\hline Kilo & 52 & 50 & 120 & 110 & $79,6 \pm 14,4$ & $70,3 \pm 13,8$ & 0,001 \\
\hline VKİ & 19,8 & 18,8 & 40 & 36,3 & $28,5 \pm 4,5$ & $25,9 \pm 4,5$ & 0,005 \\
\hline Ortalama SKB & 90 & 90 & 185 & 135 & $140,8 \pm 22,1$ & $116,2 \pm 11$ & -- \\
\hline Ortalama DKB & 60 & 55 & 130 & 90 & $89,2 \pm 13,5$ & $75,8 \pm 8,3$ & -- \\
\hline En yüksek SKB & 140 & 90 & 230 & 140 & $168,7 \pm 19$ & $118,3 \pm 11$ & -- \\
\hline En yüksek DKB & 90 & 60 & 130 & 90 & $105,1 \pm 10,9$ & $77,7 \pm 8,9$ & -- \\
\hline Kolesterol & 100 & 57 & 282 & 303 & $198,9 \pm 38,5$ & $188,5 \pm 41,2$ & 0,194 \\
\hline Trigliserid & 41 & 22 & 357 & 369 & $135,7 \pm 82,9$ & $104,6 \pm 68,8$ & $0,042 \#$ \\
\hline LDL & 64 & 54 & 198 & 200 & $133,6 \pm 32,2$ & $123,4 \pm 32,9$ & 0,119 \\
\hline HDL & 26 & 24 & 79 & 93 & $41,9 \pm 11,2$ & $44,9 \pm 15,2$ & 0,267 \\
\hline TK/HDL & 2,95 & 0,89 & 9,84 & 8,76 & $4,9 \pm 1,4$ & $4,7 \pm 1,8$ & 0,348 \\
\hline AKŞ & 73 & 73 & 144 & 129 & $95,4 \pm 12,5$ & $90,9 \pm 10$ & 0,046 \\
\hline
\end{tabular}

*V: Olgu grubu, **K: Kontrol grubu, ***S. S: Standart sapma, \# Man-Whitney U testine göre hesaplanmıştır. 
Olgu grubunda, 5 kişide (\%10) ApoE E3/E2 gen polimorfizmi, 9 kişide (\%18) ApoE E3/E4 gen polimorfizmi mevcuttu. Kontrol grubunda bu sayılar sirasiyla 7 ve 3'tü (\%14 ve \%6). Kontrol grubunda ApoE3/E2 gen polimorfizmi, kontrol grubundan daha yüksekti $(\mathrm{p}>0,05)$. Olgu grubunda E3/E4 genotipi, kontrol grubundan yüksekti; ancak bu istatiksel olarak anlamlı bir fark değildi (Tablo 2).

Apo E3/E4 allelinegenotipli hastalarda, olgu grubunda kolesterol $(203,91 \pm 26,97 \mathrm{mg} / \mathrm{dL})$ ve $\operatorname{LDL}(140,00 \pm 24,82 \mathrm{mg} / \mathrm{dL})$ ortalama değerleri, diğer genotiplere göre daha yüksekken (E2/E3 için kolesterol: 188,25 $\pm 38,79 \mathrm{mg} / \mathrm{dL}$, LDL: 114,66 $\pm 29,16 \mathrm{mg} / \mathrm{dL}$; E3/E3 için kolesterol: 192,90 \pm 41,98 mg/dL, LDL: 128,83 $\pm 33,92 \mathrm{mg} / \mathrm{dL})$, HDL değerleri daha düşüktü (E3/E4: 36,08 $\pm 10,83 \mathrm{mg} / \mathrm{dL}, \mathrm{E} 3 / \mathrm{E} 2: 43,25 \pm 13,64, \mathrm{E} 3 / \mathrm{E} 3: 44,61$ $\pm 33,51 \mathrm{mg} / \mathrm{dL}$ ). Olgu grubunda ApoE3/E4 alleline sahip olanların \%88,9'unda ailede hipertansiyon hikayesi mevcuttu. Aynı şekilde E3/E2 genotipine sahip olanların hepsinde aile hikayesi pozitifti.

Tablo 2. Olgu-kontrol grubunda genetik polimorfizmlerin dağılımı.

\begin{tabular}{llllll}
\hline $\begin{array}{l}\text { Genetik } \\
\text { polimorfizm }\end{array}$ & Mutasyon & Olgu-n (\%) & Kontrol-n (\%) & Toplam-n (\%) & Önemlilik testi \\
\hline Apo E & E3/E3 & $36(72,0)$ & $40(80,0)$ & $76(76)$ & $\mathrm{X}^{2}=3,544$ \\
& E3/E2 & $5(10,0)$ & $7(14,0)$ & $12(12)$ & $\mathrm{Sd}=2$ \\
& E3/E4 & $9(18,0)$ & $3(6,0)$ & $12(12)$ & $\mathrm{p}=0,170$ \\
& Toplam & $50(100)$ & $50(100)$ & $100(100)$ & \\
\hline \multicolumn{7}{l}{ Yüzdeler sütun yüzdesidir. *Süreklilik düzeltmeli $\mathbf{X}^{2}$ testi. } \\
\hline
\end{tabular}

Tablo 3. Aile-kontrol grubunda genetik polimorfizm dağılımı.

\begin{tabular}{llllll}
\hline $\begin{array}{l}\text { Genetik } \\
\text { polimorfizm }\end{array}$ & Mutasyon & Aile-n (\%) & Kontrol-n (\%) & Toplam-n (\%) & Önemlilik testi \\
\hline ApoE & E3/E3 & $43(86,0)$ & $40(80,0)$ & $83(83,0)$ & $\mathrm{X}^{2}=0,642$ \\
& E3/E2 & $5(10,0)$ & $7(14,0)$ & $12(12,0)$ & $\mathrm{Sd}=2$ \\
& E3/E4 & $2(4,0)$ & $3(6,0)$ & $5(5,0)$ & $\mathrm{p}>0,05$ \\
& Toplam & $50(50,0)$ & $50(50,0)$ & $100(100)$ & \\
\hline
\end{tabular}

Yüzdeler sütun yüzdesidir.

\section{Tartışma}

Apo E4'ün yüksek plazma kolesterol ve LDL ile ilişkili olduğu gösterilmiştir [29]. Çalışmamızda olgu grubunda Apo E3/E4 allelinegenotipli hastalarda, olgu grubunda kolesterol $(203,91 \pm 26,97 \mathrm{mg} / \mathrm{dL})$ ve LDL $(140,00 \pm 24,82 \mathrm{mg} / \mathrm{dL})$ ortalama değerleri, diğer genotiplere göre daha yüksek olduğu gözlemlendi (E2/E3 için kolesterol: 188,25 \pm $38,79 \mathrm{mg} / \mathrm{dL}$, LDL:114,66 \pm 29,16 mg/dL; E3/E3 için kolesterol: 192,90 $\pm 41,98 \mathrm{mg} / \mathrm{dL}$, LDL: $128,83 \pm 33,92 \mathrm{mg} / \mathrm{dL}$ ). Yapılan diğer çalı̧̧malarda da E4 alleline sahip olan kişilerde, olmayanlara göre anlamlı derecede daha yüksek LDL ve total kolesterol seviyeleri saptanmıştır $[19,27]$. Bulgularımız bu görüşü desteklemektedir.

Bhavani ve ark. [19] tarafından yapılan bir çalışmada, E4 allelinin olgu grubunda kontrole göre ve aile hikayesi pozitif olanlarda negatif olanlara göre anlamlı şekilde daha yüksek olduğu gösterilmiştir. Çalışmamızda benzer sonuçlar elde edilmiştir (Tablo 3). Olgu grubumuzda, kontrol grubuna göre daha yüksek oranda E4 alleli saptanırken (olgu: $\% 18$; kontrol \%6), E3/E4 genotipine sahip olanların \%88,9'unda ailede hipertansiyon hikayesi mevcuttu. Aile grubunda E3/E4 genotip oranı düşüktü (\%4) (Tablo 3). Ancak, bu ilişkilerin daha kesin olarak ortaya konması için daha çok çalışma yapılması gerekmektedir.

ApoE4 alleline sahip olan kişilerde, olmayanlara göre daha yüksek LDL ve total kolesterol seviyeleri saptandi. Ayrıca, E4 alleli olgu grubunda kontrole göre ve aile hikayesi pozitif olanlarda negatif olanlara göre daha yüksekti. Çalışmamızda hipertansif grupta VKİ, kolesterol, trigliserid ve LDL değerleri kontrol grubuna göre daha yüksekti. HDL değerleri her iki grupta düşük seviyelerdeydi. Hastaların çoğunun tanısı 
konduğunda hipertansiyonları Evre 2 idi. Apo E4 alleline sahip olan kişilerde, olmayanlara göre daha yüksek LDL ve total kolesterol seviyeleri saptandı. Ayrıca, E4 alleli olgu grubunda kontrole göre ve aile hikayesi pozitif olanlarda negatif olanlara göre daha yüksekti.

Başvuran tüm hastaların tansiyonu, hipertansiyon ile ilgili kılavuzlarda tavsiye edildiği şekilde muhakkak ölçülmelidir. Yüksek kan basıncı tespit edilen hastaların takibi yapılmalı, diğer risk faktörleri (VKİ, lipid profili, sigara ve alkol kullanma durumu, beslenme alışkanlıkları, vs) açısından sorgulanmalıdır. Her hastanın ilk başvurusunda bu bilgiler yer almalıdır. Hipertansiyon ve diğer kardiyovasküler hastalık ve riskler açısından aile hikayesi sorgulanmalıdır. Genç yaşta hipertansiyon tanısı konmuş ve/veya ailede hipertansiyon hikayesi olan hastalarda hipertansiyon için suçlanan genler açısından tetkikleri yapılmalıdır. Hipertansiyona genetik yatkınlığı bulunan hastaların öncelikle 1 . derece akrabalarında genetik mutasyon açısından tetkiklerini yaptırması önerilmelidir. Birinci derece akrabalarında da hipertansiyona genetik yatkınlık saptanan ailelerde tüm aile bireylerine ulaşılarak, genetik tetkiklerin yapılması sağlanmalıdır.

Genetik mutasyon saptanan ailelere danışmanlık verilmelidir. Bu ailelerin tüm bireyleri doğumdan itibaren takip edilmelidir. Birincil koruma sağlanmalı; dengeli beslenme (özellikle yă̆ ve tuz kullanımı), sigaranın bırakılması, kilo verme ve düzenli egzersiz yapılması gibi hayat tarzı değişikliklerinin uygulanması için eğitimler verilmeli ve düzenli aralıklarla kontrolleri yapılmalıdır. Hastaların ve hipertansiyon açısından riskli olan ailelerin düzenli periyotlarda sağlık muayeneleri yapılmalıdır. Hipertansif hastaların düzenli olarak antihipertansif ilaç kullanımı sağlanmalı, kılavuzlara uygun şekilde tedavi planı yapılmalıdır. Hastalar, kullanacakları ilaçlar ve yan etkileri hakkında bilgilendirilmelidir.

Çalışmamızın bazı kısıtlamaları mevcuttur. Yapılan genetik analizlerin yüksek maliyette olması ve çalışma için projeden sağlanan desteğin yeterli olmaması nedeniyle hasta popülasyonunun az sayıda olmasıdır. Verilerin değerlendirilmesinin daha anlamlı olması için daha büyük katılımcılı çalışmalar yapmak gerekmektedir. Ayrıca diğer üniversitelerde benzer çalışmalar yürütülerek gen polimorfizmi açısından farklı popülasyonların değerlendirilmesi gerekmektedir.

\section{Kaynaklar}

1. Murray CJ, Lope AD. Evidence-based health policy-lessons from the global burden of disease study. Science 1996; 274: 740-3.

2. Joint national committee on detection. Evaluation and treatment of high blood pressure. The seventh report of the Joint national committe on prevention. Detection and treatment of high blood pressure (JNC VII). JAMA 2003; 289: 2560-74.

3. Guidelines Subcommittee of the World Health Organization: World Health Organization-International society of hypertension guidelines for the management of hypertension. J Hypertens 1999; 17: 151-83.

4. Levy D, Larson MG, Vasan RS, Kannel WB, Ho KK. The progression from hypertension to congestive heart failure. JAMA 1996; 275: 1557-62.

5. Altun B, Arıc1 M, Nergizoglu G. Prevalence, awareness, treatment and control of hypertension in Turkey (the PatenT study) in 2003. Journal of hypertension 2005; 23: $1817-23$.

6. Onat A, Sansoy V, Yıılııım B. Erişkinlerimizde kan basıncı: 8-yıllık seyri, tedavi oranı, koroner kalp hastalığı ile bazı etkenlerle ilişkileri. Türk Kardiyoloji Derneği Arş 1999; 27: 136-43.

7. Sağlam K, Yılmaz Mİ, Sönmez A, Baykal Y. Primer Hipertansiyon 2003; 37.

8. Lascaux-Lefebvre V, Ruidavets J, Arveiler D. Influence of parental history of hypertension on blood pressure. J Hum Hypertens 1999; 13: 631-6.

9. Tozawa M, Oshiro S, Iseki C. Family history of hypertension and blood pressure 
in a screened cohort. Hypertens Res 2001; 24: 93-8.

10. Kikukawa N. Relationship between development of hypertension and a family history of high blood pressure in urban residents-analysis based on results of annual health examinations. Nippon Koshu Eisei Zasshi 2004; 51: 833-44.

11. Al-Safi SA, Aboul-Enein FH, Aboul-Enein BH, Manuel B. Influence of family history and lifestyle on blood pressure and heart rate in young adults in Jordan. Public Health 2006; 120: 1027-32.

12. Di Ruppo D, Farias, Guggisberg W, Delgado A. Family history as a risk factor for hypertension in adolescents. American Journal of Hypertension 2000; 13: 266.

13. Bedir A, Arık N, Adam B. Angiotensin converting enzyme gene polymorphism and activity in Turkish patients with essential hypertension. American Journal of Hypertension 1999; 12: 1038-43.

14. Maron DJ, Ridker PM, Pearson TA, Grundy S. Dislipidemi, Diğer Risk Faktörleri ve Koroner Kalp Hastalığının Önlenmesi: Fuster V. Alexander RW. O'Rourke RA: Hurst's The Heart (10.bask1) McGraw-Hill 2002; 1131-60.

15. Halperin RO, Sesso HD, Ma J. Dyslipidemia and the risk of incident hypertension in men. Hypertension 2006; 47: 45-50.

16. Sesso HD, Buring JE, Chown MJ. A prospective study of plasma lipid levels and hypertension in women. Arch Intern Med 2005; 165: 2420-7.

17. Ağaçhan B, Yılmaz H, Öztürk O. Aterosklerozda Apolipoprotein E, Okside-LDL ve Lipid Profili İlişkisinin Araştırılması F. Ü. Sağlık Bil. Dergisi 2005; 19: 193-7.

18. Mahley RW. Apolipoprotein E: Cholesterol transport protein with expanding role in cell biology. Science 1988; 240: 622-30.

19. Bhavani AB, Sastry KB, Reddy NK, Padma T. Lipid profile and apolipoprotein E polymorphism in essential hypertension. Indian Heart J 2005; 57: 151-7.

20. Imazu M, Yamamoto H, Toyofuku M et al. Association of apolipoprotein $E$ phenotype with hypertension in Japanese-Americans: Data from the Hawaii-Los Angeles-Hiroshima Study. Hypertens Res 2001; 24: 523-9.

21. Lenzen HJ., Assman G, Buckwalsky R, Schulte H. Association of apolipoprotein E polymorphism, low density lipoprotein cholesterol, and coronary artery disease. Clin Chem 1986; 32/5: 778-81.

22. Catto AJ, Kohler HP, Bannan S, Stickland M, Carter A, Grant PJ: Factor XIII Val34Leu. A novel association with primary intracerebral hemorrhage. Stroke 1998; 29: 813-6.

23. Franco RF, Pazin-Filho A, Tavella MH, Simões MV, Marin-Neto JA, Zago MA.Factor XIII val34leu and the risk of myocardial infarction. Haematologica 2000; 85: 67-71.

24. Braeckman L, De Bacquer D, Rosseneu M, De Bacquer G. Apolipoprotein E polymorphism in middle-aged Belgian men: Phenotype distribution and relation to serum lipids and lipoproteins. Atherosclerosis 1996; 120: 67-73.

25. Davignon J, Greeg RE, Sing CF. Apolipoprotein E polymorphism and atherosclerosis. Atherosclerosis 1988; 8: 1-21.

26. Hixson JE. Pathological Determinants of Atherosclerosis in Youth (PDAY) Research Group: Apolipoprotein E polymorphism affect atherosclerosis in young males. Arterioscler Thromb 1991; 11: 1237-44.

27. Jemaa R, Elasmi M, Naouali C. Apolipoprotein E polymorphism in the Tunisian population: Frequency and effect on lipid parameters. Clin Biochem 2006; 39: 816-20.

28. Yilmaz H, Isbir T, Ağaçhan B, Aydin M. Is epsilon4 allele of apolipoprotein E associated with more severe end-organ damage in essential hypertension? Cell Biochem Funct 2001; 19: 191-5.

29. Catto AJ, Kohler HP, Coore J, Mansfiel MW, Stickland MH, Grant PJ: Association of a common polymorphism in the factor XIII gene with venous thrombosis. Blood 1999; 93: 906-8. 